\title{
Research on the Cultivation of Community Social Organizations
}

\author{
Junyan Chen ${ }^{1,}{ }^{*}$,Wenjing Zhang ${ }^{2}$ \\ ${ }^{1}$ institute of political science and law, University of Jinan, Jinan,Shandong, 250000, China \\ ${ }^{2}$ Research Office,Women's Development Research Center of Shandong Province, Jinan,Shandong, 250000, China \\ *Corresponding author. Email: 610920402@qq.com
}

\begin{abstract}
With the development of society, community social organizations play an increasingly important role in the life of ordinary residents, which has a crucial role in the innovative community management mode and the improvement of the community's well-being. At present, our government attaches great importance to its development, and promotes the growth of community social organizations through the linkage of the three social organizations. Although community social organizations have played a positive role in enriching residents' lives and promoting community residents' participation in community governance, their problems in organization management, organization operations, and community service effects cannot be ignored. To promote the healthy development of community social organizations, the government needs to increase its support to community social organizations and improve the supervision system; professional social work organizations should use their professional advantages to guide the development of community social organizations on the right track. At the same time, we should give full play to the social contact role of the three social linkages to jointly promote the sustainable development of community social organizations.
\end{abstract}

Keywords: Community social organization; Three social linkage;social worker

\section{RESEARCH BACKGROUND}

After the 19th National Congress of the People's Republic of China, the "Ministry of Civil Affairs' Opinions on Vigorously Cultivating and Developing Community Social Organizations" issued by the Ministry of Civil Affairs is of great significance for the cultivation and development of community social organizations and for promoting the construction of community governance systems. The role of community social organizations is to provide community services, increase residents' participation in community affairs, cultivate and develop community culture, and promote the harmonious development of the entire community. After the 19th National Congress of the Communist Party of China, China will make greater investment in the cultivation of community social organizations, mainly from implementing classified management, clarifying the development direction, increasing financial and policy preferences, and promoting the improvement of organizational capabilities in various aspects, and continuing to promote the development of community social organizations. As society pays more and more attention to social work, more professional social workers enter the community, and the service methods are becoming more and more abundant. Therefore, community social organizations have become a very important part of social work. Under the "three social linkages" model, social workers collaborate with community management departments and community social organizations to play a vital role in the development of community social organizations.

\section{RESEARCH REVIEW}

\subsection{Review of foreign research}

Overseas research on community social organization started earlier and the content is very rich. In foreign countries, community social organizations are called "non-profit organizations" or "non-governmental organizations", also known as social groups. Community social organizations exist independently of the government, have a perfect organizational structure and operating system, and have the ability to raise funds independently. They are very systematic and standardized. In the United States, the government strongly supports the development of community social organizations and has many policy supports for its development. First of all, its registration in the United States is very simple, as long as it is legal, it can be successfully registered. Secondly, the professional social work in the United States has a long history of development, and the degree of development has been perfect so far. In addition, the United States has a set of strict and transparent related management regulations to supervise its development and protect the rights of community residents to know. The development of community social organizations in Germany is very good. The German government is very supportive of the cultivation and development of community social organizations, and has formulated relevant tax exemptions in fiscal terms. In the supervision of community social organizations, especially in terms of fund security, once the funds of community 
social organizations are abnormal, the government will ban illegal community social organizations. By strengthening the role of legal supervision and management, Germany has formed a self-disciplined and efficient community social organization environment. [1]

\subsection{Review of domestic research}

\subsubsection{Research on community social organizations}

Domestic scholars are all studying social organizations as their research objects. There are many types of community social organizations, including cultural and sports entertainment, health care, professional skills development, volunteer services and other types. With the improvement of people's awareness of voluntary service and participation in community affairs, community-based social organizations of voluntary service are increasingly favored by community residents in the community. Dou Zexiu believes that there are some similarities between community social organizations and voluntary organizations. At the same time, he has divided the categories: community foundations, community development organizations, community service organizations and community autonomous organizations. [2] Zhao Xiaoping and Tao Chuanjin believe that community social organization is a community of community residents established spontaneously by community residents. [3] In addition, Hong Kong and the Mainland are very different, it is called a regional community organization. Taiwan scholar Li Zenglu has shown in his research that community social organization is an important field of community work. It is a method and process of community work. It organizes residents, community management departments and social work organizations through organized activities to fully link all aspects. Resources to meet the development needs of communities and community residents. [4]

\subsubsection{Research on the cultivation of community social organizations}

Participants cultivated by community social organizations are mainly composed of three main bodies, namely professional social workers, community management departments and community organizations. At present, the way in which the community, community residents, and social workers work together is called "three social linkage". The research of Yu Jianxing and Jin Lei takes Hangzhou as the starting point, and proposes a model of collaborative governance between community management departments and community organizations for the problem of innovative community governance. [5] Yao Mai newly used the theory of resource dependence and believed that the most fundamental thing for the growth and growth of community social organizations is to give more support in relevant systems and regulations. [6] Zhou Yuping conducted a survey and research on the development of community social organizations in Taiyuan City, and believed that Taiyuan City should first learn from other people's advanced methods, and provide strong support in terms of policy, funding, and professional personnel to promote its rapid development. growing up [7] The main research object of Chen $\mathrm{Li}$ and Feng Xinzhuan is the community social organization in Suojin Village, Jiangsu. They found many problems. The main problems are as follows: strong administrative color, low enthusiasm of community residents, and the power of community social organizations Limited and so on, and put forward countermeasures on how to solve. [8] Lv Jingmeng's main research object is the community social organization of T Street in Beijing. The research theory is the regional development model. Taking $\mathrm{T}$ Street in Beijing as an example, he has a detailed study on the ways of social workers involved in the cultivation of community social organizations. He believes that there are four ways to cultivate community social organizations. The first is to understand social conditions and people's livelihood, and take the actual needs of residents as the entry point for the work; the second is to find community talents and community leaders and provide relevant skills training to establish community social organizations; the third is to link The resources inside and outside the community provide a more comprehensive material and policy guarantee for its cultivation; the fourth is the establishment of community social organizations directly in the community by professional social workers and community organization leaders. [9] Wang Yuanyuan's main research object is a social work institution in Nanjing. She started from the role of social work institution, mainly to study the role and role of the institution in community social organizations. She divides the cultivation of community social organizations into three types, namely supportive, college-based and autonomous. For a detailed introduction of these three different types of institutions, let us guide the different roles played by different types of nurturing institutions in the process of community social organization nurturing. [10]

\section{ANALYSIS ON THE DILEMMA AND COUNTERMEASURES OF COMMUNITY SOCIAL ORGANIZATION CULTIVATION}

\subsection{Nurturing Dilemma}

\subsubsection{Insufficient resources of policies and systems}

The Chinese government mainly promotes the cultivation and development of community social organizations in two 
ways, namely direct support and indirect support. Direct support refers to the government directly providing support in funds, and its manifestation mainly includes the government purchasing services. However, the government of our country is lagging behind in the purchase of public services, and the implementation is insufficient. The scale of government purchases of public services is limited, and these community social organizations have difficulty achieving self-sufficiency of funds. Therefore, their dependence on the government is particularly strong, resulting in social Difficulties in the initial stage of social organization. Regarding the indirect support of the government, at present, my country has not yet introduced its relevant formal laws, which has led to the confusion of the overall management of the vast majority of community social organizations, and there is no unified management standard and model.

\subsubsection{Community level}

\subsubsection{Neighborhood committee level}

At the beginning of the growth of community social organizations, their organizational norms, institutions, and autonomy are not perfect, and grassroots community management departments are required to provide administrative and financial resources for their development. These resources include related activities funds issued by the local government to the community neighborhood committees, subsidies for professional social workers, activities funds required to carry out activities, etc. In the practical work of cultivating community social organizations, the cooperative relationship between community neighborhood committees and community social organizations is not smooth. On the one hand, the workload of the neighborhood committee will increase. On the other hand, community neighborhood committees also have their own administrative indicators and work tasks, and social work organizations also have their own tasks. Therefore, when the neighborhood committees cooperate with social work organizations, they often have differences because of the naming rights of the activities and the attribution of the sponsor.

\subsubsection{Community elite}

The quality of an organization's leader directly determines the success of the organization's cultivation, and its personal ability has a decisive effect on the organization's management level and direction of organization development. Most of the leaders of community social organizations have several roles. General organization leaders are elected by the members of the organization. Their strengths are voice, leadership, and professional skills, but their disadvantages are also obvious. They lack the ability to link resources inside and outside the community, and communicate with the community neighborhood committee and social workers. Poor ability, often unable to properly solve problems. In the later period of cultivation, many problems often occur, which leads to the difficulty of operation of the organization.

\subsubsection{Insufficiency of social work organizations}

\subsubsection{Insufficient practical ability of social workers}

Many social workers have little practical experience, and there is no relevant work experience for the cultivation of community social organizations. Various problems often occur in the process of actual work, which affects the process of organizational cultivation and the effectiveness of services.

\subsubsection{Limited participation of social workers}

Many social workers only provide short-term services in the community and cannot connect with the community. The members of the community neighborhood committees and organizations have limited trust in the short-term recruitment of social workers. At the same time, they have great experience in social work practice and social organization cultivation. The big deficiency.

\subsubsection{Lack of professional supervision and guidance}

The supervisors cultivated by community social organizations lack the practical experience of first-line social workers, which is not in line with the actual situation of these communities, and it is inevitable to take detours and affect the development of services and the implementation of plans.

\subsubsection{Insufficient grasp of residents' needs}

The masses are its main body and main force, so the primary goal of its cultivation is to meet the masses' needs. However, in the work practice, the development plan of the community social organization is mainly based on the needs of the community management department and the social work organization, and the work plan is arranged, which does not reflect the dominant position of the masses. 


\subsection{Analysis on the countermeasures for the cultivation of social organizations}

\subsubsection{Policy system level}

First, it is recommended that the government publish relevant regulations and supporting documents related to the cultivation and development of community social organizations as soon as possible, and clarify the issues such as the guiding ideology, direction goals, task priorities, responsible subjects, funding sources, and safeguard measures for organization and cultivation. Second, increase financial investment in the development of community social organizations, and further increase the scale of government purchases of social work services, so that professional social work can cover the community more widely. Third, use the system to prevent violations of funds. Fourth, establish a supervision system that includes multiple participation of the government, social media, and residents to ensure the implementation of policies.

\subsubsection{Community level}

On the one hand, it actively promotes community social organizations, fully mobilizes and attracts residents to participate, and improves the recognition of community social organizations among community residents, thereby increasing the degree of participation of residents. On the other hand, the community's grassroots management department should fully respond to the specific requirements of the three social linkage projects, and effectively cooperate with professional social workers in the organization and cultivation of the community. Second, it is necessary to do a good job of training the members of the organization, nurture the residents in terms of organizational systems, business skills, etc., so that they can master the ability to independently operate community social organizations and prepare for the retirement of social workers in the later period. Once again, we should do a good job of selecting leaders in the community, do a good job of training community leaders, and provide specialized training to community leaders in organizing activities, linking resources, and coordinating relationships, etc., to improve their work and coordination skills, and make them grow into excellent Community social organizations are at the helm.

\subsubsection{Professional social work organization level}

Social worker talents should be good at linking and using social resources, give full play to their professional advantages, organize various services, conduct professional training and capacity building for community grassroots management staff and community organization leaders, and continuously improve the professional quality of organizations to cultivate relevant personnel. And business level. Social work organizations should establish a reasonable professional inheritance mechanism to reduce the negative impact on the organization's operation and the cultivation of community social organizations due to personnel changes, and ensure the quality of services. The level of supervision plays a very important role in the effectiveness and quality of social workers. Therefore, how to absorb experienced supervision is a serious challenge for social work organizations.

\subsection{4. strengthen cooperation}

The government should improve relevant laws and regulations so that its cultivation and development have a basis for law. Community neighborhood committees should make full use of community resources, do a good job of coordinated distribution of resources, clarify the responsibilities and tasks of neighborhood committees to community social organizations, earnestly fulfill their due responsibilities and obligations, and promote the completion of organizational cultivation work and implementation of activity plans. Social work organizations are mainly responsible for training members of organizations, improving the internal governance structure of community social organizations, and by cultivating community leaders, improving the professional capabilities of participants in the organization and other practical work, and ultimately making the cultivated community social organizations gradually break away from dependence on community neighborhood committees, and achieve independent and autonomous operation. The government, community neighborhood committees and social work agencies cooperate with each other to actively integrate various resources in the community, mobilize all forces, and form a joint force to promote the effective resolution of resource dilemmas and the smooth development of related cultivation work in the process of community social organization cultivation.

\section{CONCLUSION}

First, the status of community social organizations in community development is becoming more and more important, so vigorously developing community social organizations is the focus of current community work. Second, the three social linkage play a key role in the process of community work and the cultivation of community social organizations. It is necessary to make full use of operating mode of the three social linkage. Third, the main body participating in the community social organization should perform its duties, and the government, community, and social workers should give full play to their roles and carry out activities within their own responsibilities, rationally divide the labor, and form a joint force to promote the growth of community social organizations. 


\section{REFERENCES}

[1] Chen Zeshui. Analysis and Reflection on the Management Mode of American Socialized Communities[J]. Journal of Jiangxi Administration College, 2005: 33-35.

[2] Dou Zexiu, Liu Xiaojing, Li Guoyu, etc. Urban Social Governance in Transition-Taking the Social Organization Development in the Southern District of Qingdao as an Example[M]. Beijing: Social Science Literature Press, 2010: 10-12.

[3] Zhao Xiaoping, Tao Chuanjin. Community Governance: Dilemma and Outlet in Mode Transformation [M]. Beijing: Social Sciences Literature Press, 2012: 182-183.

[4] Editor-in-chief of Li Zenglu. Introduction to Social Work (Revised Third Edition) [M]. Taipei: Juliu Book Company, 2002: 178-181.

[5] Yu Jianxing, Jin Lei. The Synergy of Community Social Organizations in Social Management: Taking Hangzhou as an Example [J]. Economic and Social System Comparison, 2012: 157-168.

[6] Yao Maixin. The development of community social organizations from the perspective of resource interdependence theory takes Guangzhou as an example[J]. Lingnan Academic Journal 2012:29-35.

[7] Zhou Yuping. Research on the incubation of contemporary Chinese social organizations-Taking Taiyuan Community Social Organization Service Center as an example [J]. Social Work, 2013: 88-89.

[8] Chen Li, Feng Xinzhuan. "Three Social Linkages" and Community Management Innovation: A Case in Jiangsu [J]. Chongqing Social Sciences, 2012: 33-39.

[9] Lv Jingmeng. Research on fostering and developing community social organizations from the perspective of regional development model [D]. Capital University of Economics and Business. 2015.

[10] Wang Yuanyuan. Research on the role of nurturing institutions in the cultivation process of community social organizations-Taking three nurturing institutions as examples [D]. South Peking University. 2013. 